\title{
A Review of Registered Clinical Trials on Dietary (Poly)Phenols: Past Efforts and Possible Future Directions
}

\author{
Mirko Marino ${ }^{1,+} \oplus$, Cristian Del Bo' ${ }^{1,+} \oplus$, Daniela Martini ${ }^{1, *}\left(\mathbb{C}\right.$, Marisa Porrini ${ }^{1}(\mathbb{D}$ and \\ Patrizia Riso ${ }^{1,2}$ (D) \\ 1 Department of Food, Environmental and Nutritional Sciences (DeFENS), Università degli Studi di Milano, \\ 20133 Milan, Italy; mirko.marino@unimi.it (M.M.); cristian.delbo@unimi.it (C.D.B.); \\ marisa.porrini@unimi.it (M.P.); patrizia.riso@unimi.it (P.R.) \\ 2 CRC "Innovation for Well-Being and Environment (I-WE)", Università degli Studi di Milano, \\ 20122 Milan, Italy \\ * Correspondence: Daniela.martini@unimi.it; Tel.: +39-02-5031-6727 \\ + These authors contributed equally to this work.
}

Received: 9 October 2020; Accepted: 31 October 2020; Published: 4 November 2020

\begin{abstract}
In recent years, the increasing number of studies on polyphenol demonstrates the efforts in elucidating the potential role of these bioactives on human health. This study reviews the main topics and characteristics of clinical trials on polyphenols registered over the last 20 years, in order to track past and current efforts as well as to highlight the main research gaps in this field. The review was conducted by collecting trials registered in ClinicalTrials.gov and International Standard Randomised Controlled Trial Number (ISRCTN) registry. Overall, 750 clinical trials were selected and included in the final evaluation. Most of the trials were performed on extracts or pure compounds followed by studies conducted on polyphenol-rich foods, in particular berries. A total of 520 clinical trials focused on health effects, 55 on bioavailability, and 175 on both. Regarding outcomes, 139 registered intervention studies had the lipid profile and blood pressure as primary outcomes. The overview provided by this analysis also emphasizes the emerging interest in new outcomes related to polyphenols intervention such as microbiota composition and the evaluation of inter-individual variability in response to the intake of polyphenols. Our review underlines the need of further trials covering unexplored or debated research aspects and provides insights for the design and development of future intervention studies and related research areas.
\end{abstract}

Keywords: bioactive compounds; clinical trials; human nutrition; health outcomes; food; food extracts

\section{Introduction}

The role of dietary bioactives has gained growing importance in food and nutrition research, as demonstrated by the increase in clinical trials. Among the different classes of dietary bioactives, polyphenols have been the focus of a large number of publications over the past 20 years. For example, the published literature retrieved in PubMed with the search term "polyphenols" grew from 1383 to 9600 publications from 2000 to 2010, and in March 2020 had reached around 36,000 publications [1].

This huge increase in polyphenol research is probably firstly due to the fact that they are a large family of hundreds of secondary metabolites with a diverse structure that can be found in many different edible plants [2-5] and that are consumed daily through different food products and preparations. Secondly, there has been a substantial evolution in food and nutritional sciences observed over the past 20 years. In fact, the concept of optimal nutrition, aimed at optimizing body functions and promoting human health, has to a large extent replaced conventional nutritional recommendations 
(i.e., focused on ensuring the amount of nutrients required for growth, to avoid nutritional deficiencies and related diseases) [6].

Bioactive compounds, other than macro- and micronutrients, seem to play an important role in the context of optimal nutrition and thus need further investigation. Although these compounds are not essential, they may modulate biological and physiological functions that promote health by reducing those factors known to increase the risk of age-related chronic diseases. In fact, there is a great demand for means to promote healthy aging [7]. This is due to the rise in the mean age of the global population plus the increase in the most chronic-degenerative diseases, also known as noncommunicable diseases, such as cardiovascular diseases, cancers, respiratory diseases, and diabetes. In this regard, several studies reported the capacity of polyphenols and polyphenol-rich foods to exert antinflammatory, antioxidant and vasoactive properties [8]. In addition, polyphenols have been documented to positively modulate glucose response, blood pressure and lipid profile, thus contributing to an overall improvement of cardiometabolic health [8-10]. Furthermore, polyphenols have been recently studied for their potential role in positively influencing the gut microbiota composition [11-13].

Despite the high number of studies on polyphenols, current evidence is mostly based on findings from observational studies [14-16], as well as from in vitro studies which have revealed the potential mechanisms through which polyphenols may exert their protective effects. However, in order to clarify the effects of polyphenols on specific body functions and biological activities there is an increasing demand for clinical trials performed on target populations [17]. These studies should also consider variability of the polyphenol content of foods, as well as the high inter-individual variability (e.g., in terms of bioavailability), which might explain why some individuals benefit more than others from the intake of these bioactives [18]. Evidence from human trials can be key to providing further insights aimed at establishing dietary reference intakes for these compounds. This is because, based on current data, it is still difficult to establish an evidence-based reference intake for the whole class and all the subclasses of these compounds, and thus well-designed and methodologically sound research in this field is needed [19]. Past and current research efforts on the topic can thus be used to analyze the trends over time together with the priorities identified to date. We therefore performed a review on polyphenol research of all the registered clinical trials in the last 20 years, by retrieving the information on registries of clinical trials. The aim was to highlight the main goals of the studies and their characteristics in terms of experimental design and outcomes, also providing insights into the main research gaps in this field.

\section{Materials and Methods}

\subsection{Database Search Strategy}

Our review was conducted using "ClinicalTrials.gov" [20] and International Standard Randomised Controlled Trial Number (ISRCTN) registry [21]. The focus was on clinical trials investigating polyphenols and performed all around the world from 2000 to March 2020. The first search was conducted on 30 January 2020. Intervention studies registered in ClinicalTrials.gov and (ISRCTN). registry were searched again on 1 April 2020 to identify additional studies. The search strategies involved the combination of the following terms using a syntax that was adapted for each registry:

- ClinicalTrials.gov: polyphenols OR flavonoids OR flavanols OR anthocyanidins OR anthocyanins OR isoflavones OR flavones OR flavonols OR flavanones OR flavanonols OR nonflavonoids OR phenolic acids OR stilbenes OR lignans.

- ISRCTN registry: ("polyphenols") OR ("flavonoids") OR ("flavanols") OR ("anthocyanidins") OR ("anthocyanins") OR ("isoflavones") OR ("flavones") OR ("flavonols") OR ("flavanones") OR ("flavanonols") OR ("nonflavonoids") OR ("phenolic acids") OR ("stilbenes") OR ("lignans").

The search strategy is summarized in Figure 1. 


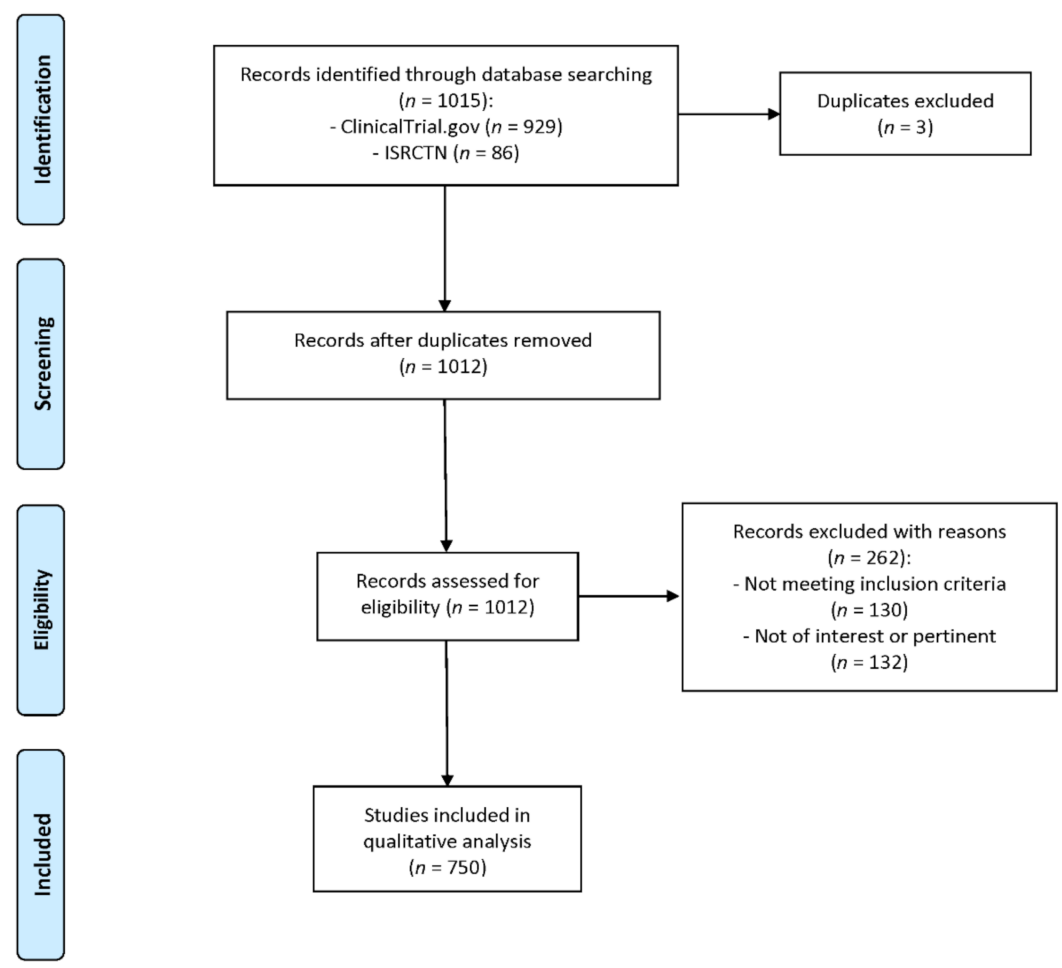

Figure 1. Flow diagram of the literature search process. Legend: ISRCTN: International Standard Randomised Controlled Trial Number.

\subsection{Study Selection}

Studies were considered eligible if they consisted of human intervention studies investigating polyphenol bioavailability or the effects of polyphenols on human health. The search was limited to clinical trials registered between 2000 and March 2020. No restrictions on the characteristics of the participants were applied and the studies were included both if the interventions concerned polyphenol-rich foods and if polyphenols were provided as extracts and/or pure compounds.

The only exclusion criteria adopted was the use of polyphenols in combination with other nutrients or dietary bioactives or drugs, in order to select studies focused only on the effects of polyphenols. No other specific restrictions for the selection of the studies were applied.

Table 1 provides a more detailed list of eligibility criteria, developed by following the Population, Intervention, Comparison, Outcome, Study design (PICOS) format [22,23].

Table 1. Population, Intervention, Comparison, Outcome, Study design (PICOS) criteria for trial selection cited.

\begin{tabular}{ll}
\hline \multicolumn{1}{c}{ PICOS Item } & \multicolumn{1}{c}{ Inclusion Criteria } \\
\hline Population & Healthy or diseased children, adults and/or older adults \\
Intervention & Food, extract or pure polyphenols tested alone. No other bioactive compound or drug \\
Comparison & Control group without polyphenols \\
Outcome & Any effect on human health and bioavailability \\
Study design & No restriction on study design \\
\hline
\end{tabular}

Two independent reviewers (M.M. and D.M.) conducted the study selection in the scientific databases and evaluated the eligibility of the clinical trials. Discrepancies between reviewers were solved through consultation with a third independent reviewer (C.D.B.) to achieve a consensus. 


\subsection{Data Extraction and Analysis}

Data extraction from the registration of intervention studies in ClinicalTrials.gov and ISRCTN registry was performed by two reviewers (M.M. and D.M.). A third author (C.D.B.) checked the extracted information in order to ensure the accuracy of the data reported. For each study, the following information was collected: registration number, registration year, location, funding, participants' information, study design, intervention, health condition, outcome measures. Studies were classified into four main categories based on their start date (2000-2004, 2005-2009, 2010-2014 and 2015-2020), similar to previous studies trends of several outcomes along the years [24-26]. Trials before 2000 were not considered while those started during the first three months of 2020 were included in the last category, from 2015 to 2020. Within these different time intervals, all studies were then further divided into two sections: polyphenol-rich foods and polyphenol-rich extracts or single pure compounds. Regarding the study location, countries were classified as "low" (number of registered studies in that country less than 10), "medium" (10 to 49) and "high" (50+).

\section{Results}

\subsection{Study Selection}

A total of 1015 registered clinical trials, conducted between January 2000 and March 2020, were identified from the database search (ClinicalTrials.gov and ISRCTN registries). After excluding 3 duplicates, 1012 records were assessed for eligibility. Out of these, 262 records were removed as they were not pertinent $(n=132)$ or because they did not match the inclusion criteria and specifically because polyphenols were provided in combination with other nutrients or bioactives $(n=97)$, or in combination with drugs $(n=33)$.

A total of 750 registered clinical trials were included in the final evaluation, as shown in Table 2. Out of these 750 clinical trials, 510 studies were chronic interventions, and 183 were acute. A total of 57 studies included both chronic and acute interventions.

Most of the studies were randomized, double-blind, placebo-controlled trials, especially if they were performed using extracts (about $80 \%$ ) rather than whole polyphenol-rich foods $(67 \%)$. The parallel-arm was the most common design for clinical trials on extracts (63\% of the studies), and the cross-over design was the most common in intervention studies on polyphenol-rich foods $(61 \%$ of the studies), with a similar trend over the years.

\subsection{Trials on Polyphenol-Rich Foods and Extracts}

Analyzing the whole period considered (2000-2020), 42\% of clinical trials were performed on polyphenol-rich foods, and $58 \%$ were conducted on extracts or pure compounds (Figure 2a). Overall, considering the different time periods (Figure $2 b, c$ ), there were more studies on extracts or pure compounds than on polyphenol-rich foods, except for 2005-2009. Moreover, studies on extracts or pure compounds increased in the different time periods, while there were fewer studies on foods in the last period compared to those in the previous five years (2010-2014). 
Table 2. Characteristics of the included studies $(n=750)$.

\begin{tabular}{|c|c|c|}
\hline & Foods $(n=315)$ & Extracts or Pure Compounds $(n=435)$ \\
\hline \multicolumn{3}{|l|}{ Goal } \\
\hline Health effect & 197 & 323 \\
\hline Bioavailability & 33 & 22 \\
\hline Both & 85 & 90 \\
\hline \multicolumn{3}{|l|}{ Duration } \\
\hline Acute & 91 & 92 \\
\hline Chronic & 194 & 316 \\
\hline Both & 30 & 27 \\
\hline \multicolumn{3}{|l|}{ Subjects } \\
\hline Healthy & 174 & 196 \\
\hline Subject with risk factors & 84 & 165 \\
\hline Patients & 57 & 74 \\
\hline \multicolumn{3}{|l|}{ Primary outcome } \\
\hline Lipid profile and blood pressure & 74 & 65 \\
\hline Vascular and endothelial function & 66 & 54 \\
\hline Glucose and insulin parameters & 40 & 52 \\
\hline Blood polyphenols' concentration & 46 & 29 \\
\hline Urinary polyphenols' concentration & 36 & 26 \\
\hline Cognitive function & 28 & 31 \\
\hline Oxidative stress & 28 & 27 \\
\hline Inflammation & 30 & 22 \\
\hline Gut Microbiota & 18 & 8 \\
\hline Safety and tolerability & 4 & 19 \\
\hline Other & 98 & 122 \\
\hline \multicolumn{3}{|l|}{ Location } \\
\hline USA & 94 & 136 \\
\hline UK & 76 & 72 \\
\hline Spain & 23 & 35 \\
\hline Canada & 21 & 22 \\
\hline Italy & 17 & 20 \\
\hline Germany & 13 & 21 \\
\hline China & 4 & 24 \\
\hline Netherlands & 4 & 18 \\
\hline France & 6 & 14 \\
\hline Switzerland & 10 & 5 \\
\hline Other & 47 & 68 \\
\hline
\end{tabular}

\subsubsection{Types of Polyphenol-Rich Foods}

Berries were the most studied foods (Figure 3a), with a total of 99 registered trials, increasing (Figure 3b) up to 49 intervention studies from 2015 to 2020 . Other frequently studied foods were cocoa and dark chocolate (33 and 29 clinical trials respectively, in the 20-year period considered) although from 2015 to 2020 fewer than $10 \%$ and 5\%, respectively, of the 112 interventions focused on these products. Orange and orange juice, cereals, red wine, olive oil, green tea, soy and pomegranates accounted for a total of 94 studies, that is almost one third of all studies on polyphenol-rich foods. Finally, the category "other" included (i) generally less studied food sources (such as apples, coffee, potatoes, pulses and beer) and (ii) products were mainly considered in the last few years (such as hazelnuts, almonds, artichokes, mangos and dates). 
a)

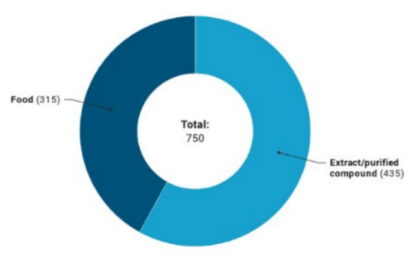

b)

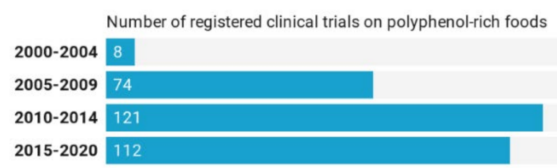

c)

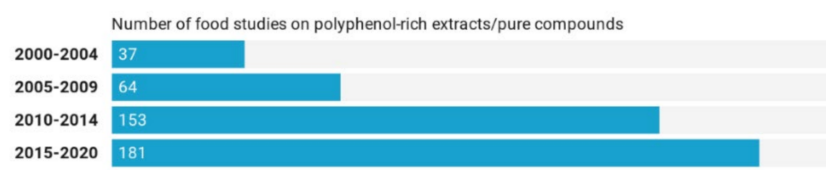

Figure 2. Number (a) and trend of registered trials on polyphenol-rich foods (b) and extracts or pure compounds (c).

a)

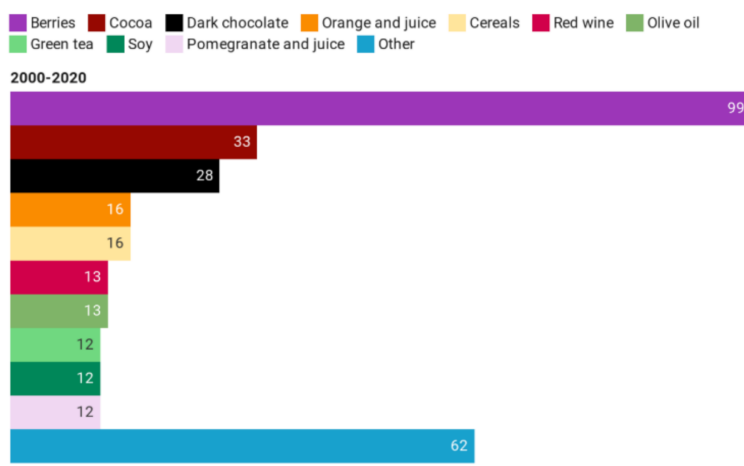

b)

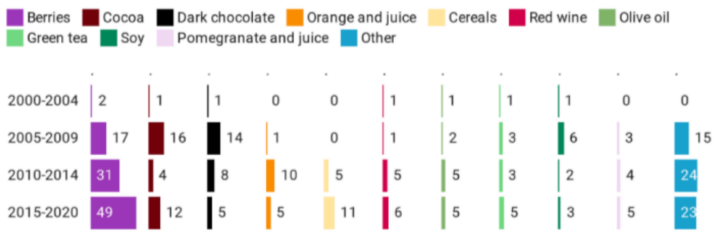

Figure 3. Main polyphenol-rich foods (a) used in clinical trials and their trend (b).

\subsubsection{Types of Polyphenol-Rich Extracts}

Similarly to polyphenol-rich foods, the category of berries was the most studied ( $27 \%$ of the registered studies) (Figure 4a) also among intervention studies with extracts, with a constant increase over the years (Figure 4b). The second most studied category was soy extract whose interest, unlike berries, decreased over the years, from 28 trials between 2000 and 2004 to only 2 registered intervention studies from 2015 to 2020 . Other food extracts studied included combinations of different 
food extracts (defined in Figure 4a as "PR-extract", $n=48$ ) and cocoa, green tea, pomegranates, flaxseeds and apple extracts which overall were considered in 92 studies.

a)

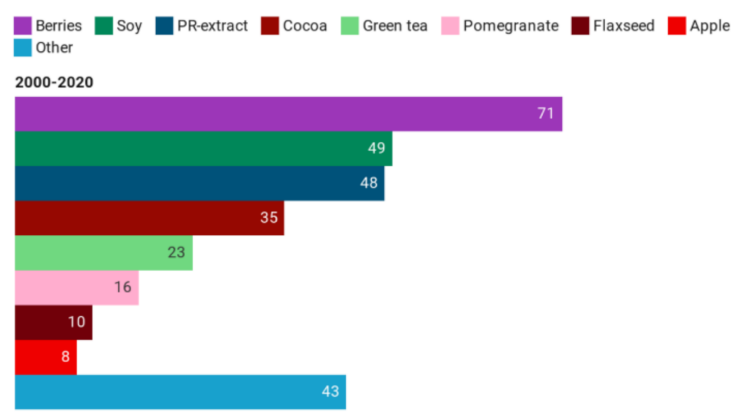

b)

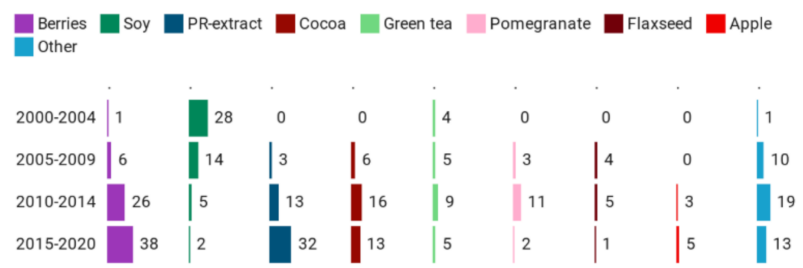

Figure 4. Main polyphenol-rich extracts (a) used in clinical trials and their trend (b).

\subsubsection{Types of Pure (Poly)Phenolic Compounds}

Figure 5a depicts the most considered classes of pure (poly)phenolic compounds used in registered clinical trials over the last 20 years. Flavanols were the most investigated class of polyphenols ( $n=45$ studies), followed by anthocyanidins $(n=31)$ and isoflavones $(n=29)$. However, as shown in Figure $5 b$, their trend differed according to the number of studies for each of the four periods. For instance, the highest number of registered trials in the 2010-2014 period focused on flavanols and isoflavones and then decreased in the last five years. Conversely, there was a growing trend for anthocyanidins for which there were no registered studies from 2000 to 2004 and 20 interventions from 2015 to today ( $27 \%$ of total studies on pure compounds in the last five years), thus becoming the most studied class of polyphenols.

a)

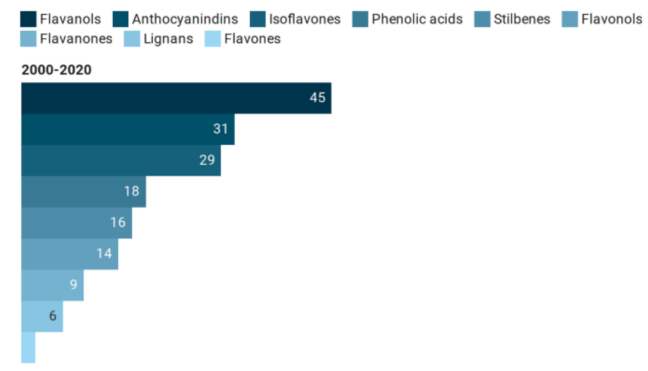

b)

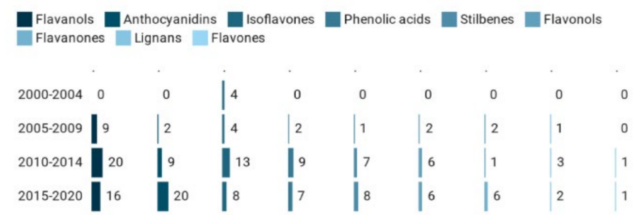

Figure 5. Main classes of pure polyphenols used in clinical trials (a) and their trend (b). 


\subsection{Characteristics of Subjects}

Regarding the characteristics of the participants (Figure 6), most of the trials on polyphenols were conducted on healthy subjects ( $n=370$ studies, $49 \%$ ), followed by studies on subjects with diseases such as cancer, urogenital diseases and mental disorders $(n=249,33 \%)$, and then subjects with risk factors such as high blood pressure, fasting glucose and triglyceride levels $(n=131,18 \%)$. Concerning age, 438 registered clinical trials included both adults and older subjects, 286 studies included only adults, 14 studies included only older individuals while 12 studies focused on children.

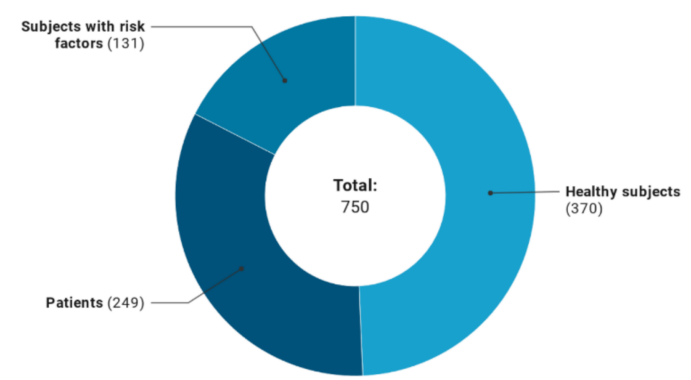

Figure 6. Health status of subjects included in the registered clinical trials.

Registered clinical trials on polyphenols were balanced in terms of the participants' sex, with 109 studies only on females and 114 studies only on males, while 527 studies included both sexes.

\subsection{Main Goals of the Registered Trials}

Figure 7a shows the main goals of the registered trials. A total of 520 clinical trials (197 on foods and 323 on extracts) focused on health effects, 55 ( 33 on polyphenol-rich foods and 22 on extracts) on bioavailability and 175 ( 85 on polyphenol-rich foods and 90 on extracts) evaluated both. Figure $7 \mathrm{~b}$ highlights intervention studies on health effects increased over time, from 43 registered trials from 2000 to 2004, to 205 in the last five years. On the other hand, studies on bioavailability increased throughout the first three time periods ( $n=0,9$ and 26, respectively) and then decreased in the 2015-2020 period $(n=20)$, similarly to studies assessing both health effects and bioavailability.

a)

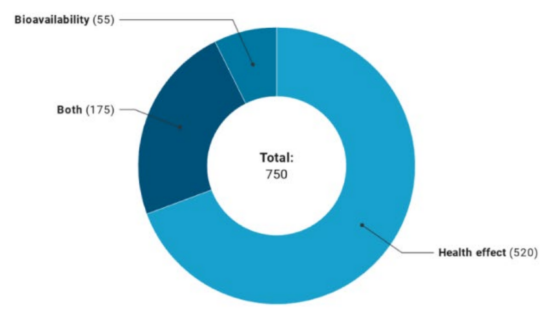

b)

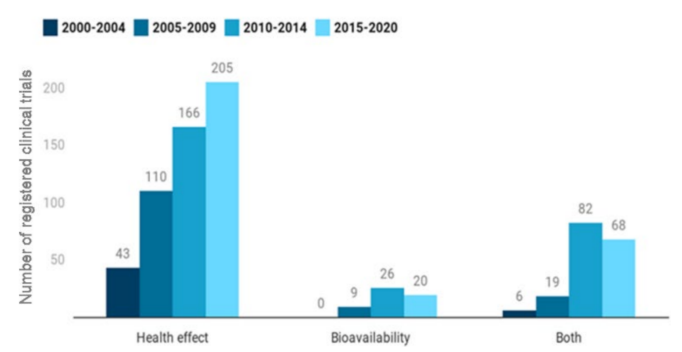

Figure 7. Number (a) and trend (b) of studies assessing the bioavailability or the health effects of polyphenols. 
The outcomes of the registered trials are reported in Figure 8a. Lipid profile and blood pressure were the primary outcomes in 139 registered intervention studies, with a constant increase in absolute terms (from 7 in 2000-2004, to 34, 44 and 54 in the 2005-2009, 2010-2014, 2015-2020, respectively) but not in relative terms (e.g., 25\% of the studies during the 2005-2009 period and 17\% in the last five years) (Figure 8b). A similar trend was observed for studies on vascular and endothelial function, which had the highest number of interventions from 2005 to 2009.

a)

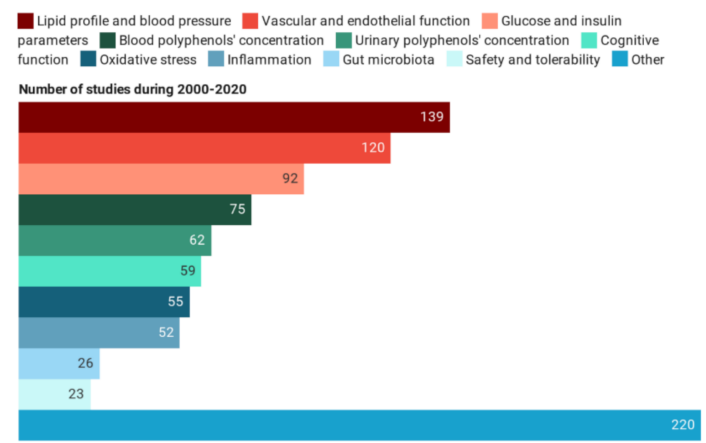

b)

Figure 8. Primary outcomes (a) and their trend (b) assessed during clinical trials on polyphenols.

In addition, glucose and insulin parameters were widely investigated, with a total of 92 intervention studies from 2000 to 2020 . The number of studies on cancer and osteoporosis was high between 2000 and 2004 ( $23 \%$ and $21 \%$ of the total studies, respectively) and decreased drastically over time, accounting for $1 \%$ of the registered trials. Conversely, significant interest was recorded from 2015-2020 in primary outcomes that were neglected in the past, such as the modification in urinary polyphenol concentration and gut microbiota.

\subsection{Other Characteristics of the Registered Trials}

Figure 9 reports the main countries where clinical trials on polyphenol-rich foods (Figure 9a) and extracts (Figure $9 b$ ) were registered. In each of the five-year periods considered, the highest number of registered studies was in the USA (230 clinical trials: 136 on extracts and 94 on polyphenol-rich foods) and in the UK (148 trials: 72 on extracts and 76 on foods). A significant number of interventions was also registered in Spain $(n=58)$, Canada $(n=43)$, Italy $(n=37)$, Germany $(n=34)$, China $(n=28)$, The Netherlands ( $n=22)$, France $(n=20)$, Brazil $(n=17)$ and Switzerland $(n=15)$.

Other important information concerns the funding of the studies. A total of 580 and 170 registered clinical trials were supported by private and public funding, respectively, with a constant and increasing gap between the two types of funding. In fact, while public funding was prevalent from 2000 to 2004, the number of studies with private funding was threefold and fivefold those with public funding in the 2005-2010 and 2015-2020 periods, respectively. 


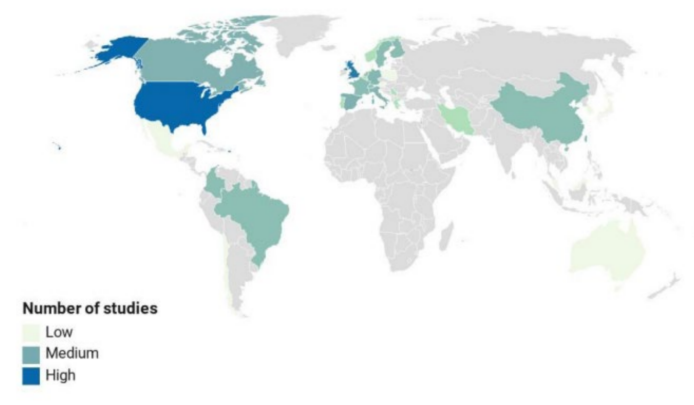

b)

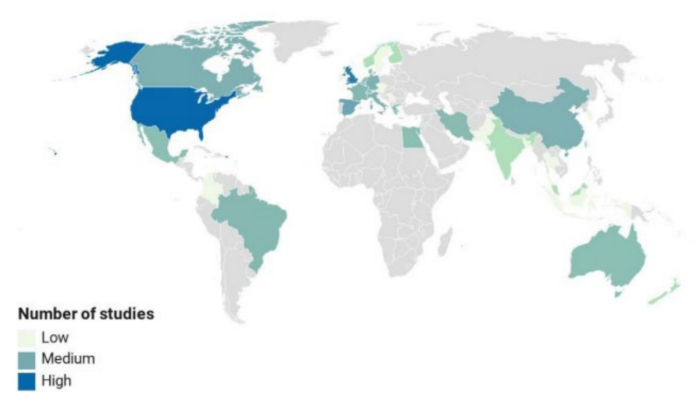

Figure 9. Countries with the highest number of registered studies on polyphenol-rich foods (a) and extracts (b). Legend: "low": <10 registered trials; "medium": 10-49 registered trials; "high": $>50$ registered trials. Locations not reporting clinical trials on polyphenols are colored in grey.

\section{Discussion}

Human intervention studies are always in more demand due to the putative effects of food bioactives such as polyphenols. For the first time, we have documented the high number of human intervention studies on polyphenols currently registered in two of the main registries of clinical trials (i.e., 750 registered clinical trials included in the final evaluation), thus demonstrating the continuous and increasing interest in the role of these food bioactives. This is also supported by the high number of publications, together with the growing number of national and international research projects focused on polyphenols. Moreover, polyphenols represent an interesting and clear example of compounds that have attracted the attention of researchers from many different disciplines. First, there is a growing interest in the evaluation of the environmental, agronomic and pre-harvest aspects that can affect the polyphenol content in foods [27-29]. Secondly, food technology is making efforts to optimize traditional technologies and to develop novel techniques able to preserve the natural content of polyphenols in the raw materials as well as to use polyphenol-rich ingredients for food fortification [30-34]. Thirdly, experts in the nutrition and health related areas are committed to increase evidence in order to understand if and how it can be possible to develop dietary recommendations for polyphenols intake $[9,19,35-37]$, also considering the demand for healthy and sustainable diets to be promoted as a potential climate change mitigation strategy. For these reasons, numerous different stakeholders, both in the private and public sector, seem to show a great interest for the potential applications of results from polyphenol research.

Regarding clinical trials, our findings show that chronic intervention studies tend to be more common than acute ones, above all in the last years. This implies a shift from studies mostly addressing polyphenol bioavailability to chronic trials that are more often focused on the evaluation of the medium and long-term effects of polyphenol intake on human health. 
In view of the complexity of polyphenol pharmacokinetics and the increasing knowledge of the inter-individual variability in terms of absorption, distribution and metabolism affecting human responses to polyphenol intake [38-40], further studies are needed to better explore this variability and how this influences the impact of polyphenols on markers of human health [18,41-43]. These should also address the metabolic activities of microbiota. In fact, the importance of the microbiota-host interplay in comprehending the impact of polyphenols, and of diet in general, on human health is only recently emerging [39]. In detail, evidence suggests that polyphenols may act through modulation of the gut microbiota composition [44]. In turn, gut microbiota significantly affects the metabolic fate of plant polyphenols, as they undergo extensive metabolism leading to the release in the bloodstream of smaller and more polar metabolites which may be the responsible of several biological effects [12,45-47]. Taken together, these findings highlight the need to study the metabolism and health benefits together, rather than separately.

The increasing number of long-term and well-designed trials is an important achievement in terms of furthering our understanding of polyphenol intake (e.g., quantity and duration), which could lead to future recommendations regarding intake for the positive modulation of specific physiological functions [19]. Since these studies are costly, time-consuming, and often difficult to design and perform, their growing number suggests an increased investment in addressing the role of polyphenols in real settings and human subgroups of the population. In addition, it is noteworthy that studies on healthy or at-risk individuals prevail, in line with the guidance of the European Food Safety Authority reporting that subjects with a disease cannot be the target population for demonstrating a health claim made on food [48].

The high number of studies on the lipid profile, blood pressure, endothelial function and other related markers clearly highlights the wide interest in understanding the effects of polyphenols on cardiometabolic health. This is not surprising considering that, as highlighted by the Global Burden of Disease study [49], cardio-metabolic diseases are the leading cause of death worldwide, mainly triggered by the rise in biomarkers of metabolic syndrome, including waist circumference, fasting blood glucose, triglycerides, and blood pressure. Studies have underlined how a diet rich in plant-based foods, such as fruit and vegetables, could decrease the risk of these metabolic diseases, thanks to their content of fiber, vitamins, minerals but also bioactive compounds such as polyphenols $[50,51]$ that can play an important role in the regulation of the redox status of cells. In addition they can improve endothelial function and vessel protection but also increase nitric oxide bioavailability, thus, playing a role on the maintenance of normal levels of blood pressure and on the inhibition of platelet aggregation $[52,53]$.

In our review, there were less studies on the effects of polyphenol-rich foods than those investigating the effects of extracts or pure compounds, which are mostly used for investigating their bioavailability. This could be due to the increased interest in the industrial exploitation and development of food extracts for use as nutraceuticals. In details, among polyphenol-rich foods, there is still a great interest in berries due to their high content in phenolic compounds, such as phenolic acids, flavonols and anthocyanins and there are many papers demonstrating their positive role in the modulation of several physiological functions [54-57]. Conversely, a minor number of trials assessed the study of other polyphenol-rich foods on different outcomes, although evidence supports the positive role of other polyphenol-rich foods on markers of human health [58-63]. This may be due a lower interest and/or, more plausibly, to the lower availability of funding. In this regard, berries have also attracted private investments, probably being considered attractive and versatile foods for their exploitation in the pharmaceutical and food industry area. Funding could thus be increased in order to evaluate the effects of the combination of different foods and of polyphenol-rich diets, in order to provide insights into the role of these dietary models in a real-life setting.

We believe that a key strength of our study is that we opted to review registered trials rather than published papers in order to ensure a more up-to-date picture of the current research on a specific topic, also considering that papers are often published much later than the registration date and even the real end of the study. For instance, with this approach we were able to collect information of very recently 
registered trials, whose results will be likely published in the next few years. Moreover, within the registration form of a trial, the authors report some information that is sometimes not very clear in the manuscript (e.g., primary outcome, characteristics of subjects, funding). In fact, other reviews have analyzed registered clinical trials, for instance for investigating the characteristics of general registered trials [64], including sponsorship [65], or of specific topics such as ophthalmology [66], orthodontics [67], infection diseases [68], drug trials [69]. However, our review also has some limitations. First, the use of websites of trial registration does not allow to retrieve sufficient information to perform the risk of bias assessment, for instance because findings of the study are not included and thus, the bias of selection of the reported results and those of deviations from the intended intervention cannot be assessed [70]. Secondly, ClinicalTrials.gov and ISRCTN databases do not include all clinical trials as they are not the only databases available. Moreover, some trials may have not been included in the final evaluation, because they were not yet registered or because they did not use the keywords appropriately. An additional limitation could be that we excluded some clinical trials in which polyphenols were not the main bioactive compounds considered [71]. In this general context, it is emphasized the importance and relevance of the promotion and implementation of the practice of registering clinical trials for the analysis of trends and gaps in a research area.

\section{Conclusions}

Despite numerous data from literature have shown a protective role of polyphenols on human health, findings from the present review show that there is still a need of studies to fill several gaps in this field, also by considering the different factors such as individual response that could affect polyphenols bioavailability and bioactivity. In this scenario, databases such as ClinicalTrials.gov and ISRCTN. registry may play a key role to monitor registered intervention studies with the aim to track already ongoing research. The present work provides indeed useful insights to be used for the design of future studies in the field of polyphenols that will increase knowledge about the complex interaction between these compounds and the host in terms of bioavailability and biological response and their exploitation for the promotion of human health. The last but not the least, findings from such studies could provide a rationale and a driving force for activities aimed at improving nutritional profiles of promising products pushing towards the innovation in production, processing and the whole food system approach.

Author Contributions: Conceptualization, P.R., C.D.B., M.P.; methodology, M.M., C.D.B., D.M.; formal analysis, M.M., C.D.B., D.M.; writing—original draft preparation, M.M., C.D.B.; writing—-review and editing, P.R., D.M., M.P.; supervision, P.R., M.P. All authors have read and agreed to the published version of the manuscript.

Funding: C.D.B. is grateful for support granted by "Piano di sostegno alla ricerca-Linea 2, azione A"-grant number "PSR2019-CDELB".

Acknowledgments: This research was developed within the general objectives promoted through MIND FoodS Hub: Innovative concept for the eco-intensification of agricultural production and for the promotion of dietary patterns for human health and longevity through the creation in MIND of a digital Food System Hub (P.O.R. 2014-2020_BANDO Call HUB Ricerca e Innovazione_D.G.R. NR 727 del 5/11/2018). P.R. and C.D.B. acknowledge the SYSTEMIC project (ERA-HDHL Knowledge Hub on Food and Nutrition Security) with national funding support provided by Mipaaf (MIMOSA project, DG DISR-DISR 04-Prot. Uscita N.0041532, 23/12/2019) and MAPLE project (Gut and blood microbiomics for studying the effect of a polyphenol-rich dietary pattern on intestinal permeability in the elderly), which was funded through JPI-HDHL-http://www.healthydietforhealthylife.eu/) with national funding support provided by Mipaaf (Italy; D.M. 8245/7303/2016). P.R. and C.D.B. also are grateful to the European Cooperation for Science and Technology (COST Action) CA16112 “NutRedOx: Personalized Nutrition in Aging Society: Redox Control of Major Age-related Diseases".

Conflicts of Interest: The authors declare no conflict of interest.

\section{References}

1. PubMed. Available online: https://pubmed.ncbi.nlm.nih.gov/ (accessed on 30 April 2020).

2. Adebooye, O.C.; Alashi, A.M.; Aluko, R.E. A brief review on emerging trends in global polyphenol research. J. Food Biochem. 2018, 42, e12519. [CrossRef] 
3. Abbas, M.; Saeed, F.; Anjum, F.M.; Afzaal, M.; Tufail, T.; Bashir, M.S.; Ishtiaq, A.; Hussain, S.; Suleria, H.A.R. Natural polyphenols: An overview. Int. J. Food Prop. 2017, 20, 1689-1699. [CrossRef]

4. Pérez-Jiménez, J.; Neveu, V.; Vos, F.; Scalbert, A. Identification of the 100 richest dietary sources of polyphenols: An application of the Phenol-Explorer database. Eur. J. Clin. Nutr. 2010, 64, S112-S120. [CrossRef] [PubMed]

5. D'Archivio, M.; Filesi, C.; Di Benedetto, R.; Gargiulo, R.; Giovannini, C.; Masella, R. Polyphenols, dietary sources and bioavailability. Ann. Ist. Super. Sanita 2007, 43, 348-361. [PubMed]

6. Fraga, C.G.; Oteiza, P. Bioactives and their impact on human health. Mol. Asp. Med. 2018, 61, 1. [CrossRef]

7. Jin, K. New perspectives on healthy aging. Prog. Neurobiol. 2017, 157, 1. [CrossRef]

8. Fraga, C.G.; Croft, K.D.; Kennedy, D.O.; Tomás-Barberán, F.A. The effects of polyphenols and other bioactives on human health. Food Funct. 2019, 10, 514-528. [CrossRef]

9. Giacco, R.; Costabile, G.; Fatati, G.; Frittitta, L.; Maiorino, M.I.; Marelli, G.; Parillo, M.; Pistis, D.; Tubili, C.; Vetrani, C.; et al. Effects of polyphenols on cardio-metabolic risk factors and risk of type 2 diabetes. A joint position statement of the Diabetes and Nutrition Study Group of the Italian Society of Diabetology (SID), the Italian Association of Dietetics and Clinical Nutrition (ADI) and the Italian Association of Medical Diabetologists (AMD). Nutr. Metab. Cardiovasc. Dis. 2020, 30, 355-367.

10. Gibney, E.R.; Milenkovic, D.; Combet, E.; Ruskovska, T.; Greyling, A.; González-Sarrías, A.; de Roos, B.; Tomás-Barberán, F.; Morand, C.; Rodriguez-Mateos, A. Factors influencing the cardiometabolic response to (poly)phenols and phytosterols: A review of the COST Action POSITIVe activities. Eur. J. Nutr. 2019, 58, 37-47. [CrossRef]

11. Tomás-Barberán, F.A.; Selma, M.V.; Espín, J.C. Interactions of gut microbiota with dietary polyphenols and consequences to human health. Curr. Opin. Clin. Nutr. Metab. Care 2016, 19, 471-476. [CrossRef] [PubMed]

12. Cardona, F.; Andrés-Lacueva, C.; Tulipani, S.; Tinahones, F.J.; Queipo-Ortuño, M.I. Benefits of polyphenols on gut microbiota and implications in human health. J. Nutr. Biochem. 2013, 24, 1415-1422. [CrossRef] [PubMed]

13. Shortt, C.; Hasselwander, O.; Meynier, A.; Nauta, A.; Fernández, E.N.; Putz, P.; Rowland, I.; Swann, J.; Türk, J.; Vermeiren, J.; et al. Systematic review of the effects of the intestinal microbiota on selected nutrients and non-nutrients. Eur. J. Nutr. 2018, 57, 25-49. [CrossRef]

14. Godos, J.; Vitale, M.; Micek, A.; Ray, S.; Martini, D.; Del Rio, D.; Riccardi, G.; Galvano, F.; Grosso, G. Dietary Polyphenol Intake, Blood Pressure, and Hypertension: A Systematic Review and Meta-Analysis of Observational Studies. Antioxidants 2019, 8, 152. [CrossRef]

15. Pham, N.M.; Do, V.V.; Lee, A.H. Polyphenol-rich foods and risk of gestational diabetes: A systematic review and meta-analysis. Eur. J. Clin. Nutr. 2019, 73, 647-656. [CrossRef]

16. Rienks, J.; Barbaresko, J.; Nöthlings, U. Association of Polyphenol Biomarkers with Cardiovascular Disease and Mortality Risk: A Systematic Review and Meta-Analysis of Observational Studies. Nutrients 2017, 9, 415.

17. Renaud, J.; Martinoli, M. Considerations for the Use of Polyphenols as Therapies in Neurodegenerative Diseases. Int. J. Mol. Sci. 2019, 20, 1883. [CrossRef] [PubMed]

18. Ruskovska, T.; Maksimova, V.; Milenkovic, D. Polyphenols in human nutrition: From the in vitro antioxidant capacity to the beneficial effects on cardiometabolic health and related inter-individual variability-An overview and perspective. Br. J. Nutr. 2020, 123, 241-254. [CrossRef] [PubMed]

19. Del Bo', C.; Bernardi, S.; Marino, M.; Porrini, M.; Tucci, M.; Guglielmetti, S.; Cherubini, A.; Carrieri, B.; Kirkup, B.; Kroon, P.; et al. Systematic Review on Polyphenol Intake and Health Outcomes: Is there Sufficient Evidence to Define a Health-Promoting Polyphenol-Rich Dietary Pattern? Nutrients 2019, 11, 1355.

20. ClinicalTrials Registry. Available online: https://clinicaltrials.gov (accessed on 30 April 2020).

21. ISRCTN Registry. Available online: https://www.isrctn.com (accessed on 30 April 2020).

22. Saaiq, M.; Ashraf, B. Modifying "Pico" Question into "Picos" Model for More Robust and Reproducible Presentation of the Methodology Employed in A Scientific Study. World J. Plast. Surg. 2017, 6, 390-392. [PubMed]

23. Methley, A.M.; Campbell, S.; Chew-Graham, C.; McNally, R.; Cheraghi-Sohi, S. PICO, PICOS and SPIDER: A comparison study of specificity and sensitivity in three search tools for qualitative systematic reviews. BMC Health Serv. Res. 2014, 14, 579. [CrossRef]

24. Guru Murthy, G.S.; Szabo, A.; Michaelis, L.; Carlson, K.-S.; Runaas, L.; Abedin, S.; Atallah, E. Improving Outcomes of Acute Promyelocytic Leukemia in the Current Era: Analysis of the SEER Database. J. Natl. Compr. Cancer Netw. 2020, 18, 169-175. 
25. Parikh, S.H.; Satwani, P.; Ahn, K.W.; Sahr, N.A.; Fretham, C.; Abraham, A.A.; Agrawal, V.; Auletta, J.J.; Abdel-Azim, H.; Copelan, E.; et al. Survival Trends in Infants Undergoing Allogeneic Hematopoietic Cell Transplant. JAMA Pediatr. 2019, 173, e190081. [CrossRef]

26. Chen, Y.; Chomsky-Higgins, K.; Nwaogu, I.; Gosnell, J.E.; Seib, C.; Shen, W.T.; Suh, I.; Duh, Q.-Y. Trends in Adrenal Surgery-The Changing Nature of Tumors and Patients. J. Surg. Res. 2019, 236, 129-133. [CrossRef]

27. Blanch, G.P.; Gómez-Jiménez, M.C.; Ruiz del Castillo, M.L. Enrichment of Olive Fruits in Antioxidant Content by Pre-Harvest Salicylic Acid Treatment. Foods 2020, 9, 1513. [CrossRef]

28. Martini, D.; Taddei, F.; Nicoletti, I.; Ciccoritti, R.; Corradini, D.; D’Egidio, M.G. Effects of Genotype and Environment on Phenolic Acids Content and Total Antioxidant Capacity in Durum Wheat. Cereal Chem. J. 2014, 91, 310-317. [CrossRef]

29. Struiving, S.; Hacke, A.C.M.; Simionatto, E.L.; Scharf, D.R.; Klimaczewski, C.V.; Besten, M.A.; Heiden, G.; Boligon, A.A.; Rocha, J.B.T.; Vellosa, J.C.R.; et al. Effects of Gender and Geographical Origin on the Chemical Composition and Antiradical Activity of Baccharis myriocephala and Baccharis trimera. Foods 2020, 9, 1433. [CrossRef] [PubMed]

30. Alashi, A.M.; Taiwo, K.A.; Oyedele, D.J.; Adebooye, O.C.; Aluko, R.E. Polyphenol composition and antioxidant properties of vegetable leaf-fortified bread. J. Food Biochem. 2019, 43, e12625. [CrossRef] [PubMed]

31. Antonic, B.; Jancikova, S.; Dordevic, D.; Tremlova, B. Apple pomace as food fortification ingredient: A systematic review and meta-analysis. J. Food Sci. 2020, 85, 2977-2985. [CrossRef]

32. McDougall, G.J. Phenolic-enriched foods: Sources and processing for enhanced health benefits. Proc. Nutr. Soc. 2017, 76, 163-171. [CrossRef]

33. Martini, D.; Ciccoritti, R.; Nicoletti, I.; Nocente, F.; Corradini, D.; D’Egidio, M.G.; Taddei, F. From seed to cooked pasta: Influence of traditional and non-conventional transformation processes on total antioxidant capacity and phenolic acid content. Int. J. Food Sci. Nutr. 2018, 69, 24-32. [CrossRef]

34. Pycia, K.; Ivanišová, E. Physicochemical and Antioxidant Properties of Wheat Bread Enriched with Hazelnuts and Walnuts. Foods 2020, 9, 1081. [CrossRef] [PubMed]

35. Cory, H.; Passarelli, S.; Szeto, J.; Tamez, M.; Mattei, J. The Role of Polyphenols in Human Health and Food Systems: A Mini-Review. Front. Nutr. 2018, 5, 87. [CrossRef]

36. Koch, W. Dietary Polyphenols-Important Non-Nutrients in the Prevention of Chronic Noncommunicable Diseases. A Systematic Review. Nutrients 2019, 11, 1039. [CrossRef]

37. Rasouli, H.; Farzaei, M.H.; Khodarahmi, R. Polyphenols and their benefits: A review. Int. J. Food Prop. 2017, 1-42. [CrossRef]

38. Manach, C.; Milenkovic, D.; Van de Wiele, T.; Rodriguez-Mateos, A.; de Roos, B.; Garcia-Conesa, M.T.; Landberg, R.; Gibney, E.R.; Heinonen, M.; Tomás-Barberán, F.; et al. Addressing the inter-individual variation in response to consumption of plant food bioactives: Towards a better understanding of their role in healthy aging and cardiometabolic risk reduction. Mol. Nutr. Food Res. 2017, 61, 1600557. [CrossRef]

39. Bento-Silva, A.; Koistinen, V.M.; Mena, P.; Bronze, M.R.; Hanhineva, K.; Sahlstrøm, S.; Kitryte, V.; Moco, S.; Aura, A.-M. Factors affecting intake, metabolism and health benefits of phenolic acids: Do we understand individual variability? Eur. J. Nutr. 2020, 59, 1275-1293. [CrossRef]

40. Gross, G.; Jacobs, D.M.; Peters, S.; Possemiers, S.; van Duynhoven, J.; Vaughan, E.E.; van de Wiele, T. In Vitro Bioconversion of Polyphenols from Black Tea and Red Wine/Grape Juice by Human Intestinal Microbiota Displays Strong Interindividual Variability. J. Agric. Food Chem. 2010, 58, 10236-10246. [CrossRef] [PubMed]

41. Martini, D.; Chiavaroli, L.; González-Sarrías, A.; Bresciani, L.; Palma-Duran, S.A.; Dall'Asta, M.; Deligiannidou, G.-E.; Massaro, M.; Scoditti, E.; Combet, E.; et al. Impact of Foods and Dietary Supplements Containing Hydroxycinnamic Acids on Cardiometabolic Biomarkers: A Systematic Review to Explore Inter-Individual Variability. Nutrients 2019, 11, 1805. [CrossRef]

42. García-Conesa, M.-T.; Chambers, K.; Combet, E.; Pinto, P.; Garcia-Aloy, M.; Andrés-Lacueva, C.; de Pascual-Teresa, S.; Mena, P.; Konic Ristic, A.; Hollands, W.; et al. Meta-Analysis of the Effects of Foods and Derived Products Containing Ellagitannins and Anthocyanins on Cardiometabolic Biomarkers: Analysis of Factors Influencing Variability of the Individual Responses. Int. J. Mol. Sci. 2018, 19, 694. 
43. González-Sarrías, A.; García-Villalba, R.; Romo-Vaquero, M.; Alasalvar, C.; Örem, A.; Zafrilla, P.; Tomás-Barberán, F.A.; Selma, M.V.; Espín, J.C. Clustering according to urolithin metabotype explains the interindividual variability in the improvement of cardiovascular risk biomarkers in overweight-obese individuals consuming pomegranate: A randomized clinical trial. Mol. Nutr. Food Res. 2017, 61, 1600830.

44. Lavefve, L.; Howard, L.R.; Carbonero, F. Berry polyphenols metabolism and impact on human gut microbiota and health. Food Funct. 2020, 11, 45-65. [CrossRef] [PubMed]

45. Catalkaya, G.; Venema, K.; Lucini, L.; Rocchetti, G.; Delmas, D.; Daglia, M.; De Filippis, A.; Xiao, H.; Quiles, J.L.; Xiao, J.; et al. Interaction of dietary polyphenols and gut microbiota: Microbial metabolism of polyphenols, influence on the gut microbiota, and implications on host health. Food Front. 2020, 1, 109-133. [CrossRef]

46. Mena, P.; Bresciani, L.; Brindani, N.; Ludwig, I.A.; Pereira-Caro, G.; Angelino, D.; Llorach, R.; Calani, L.; Brighenti, F.; Clifford, M.N.; et al. Phenyl- $\gamma$-valerolactones and phenylvaleric acids, the main colonic metabolites of flavan-3-ols: Synthesis, analysis, bioavailability, and bioactivity. Nat. Prod. Rep. 2019, 36, 714-752. [CrossRef]

47. Corrêa, T.A.F.; Rogero, M.M.; Hassimotto, N.M.A.; Lajolo, F.M. The Two-Way Polyphenols-Microbiota Interactions and Their Effects on Obesity and Related Metabolic Diseases. Front. Nutr. 2019, 6, 188.

48. European Food Safety Authority (EFSA) Panel on Dietetic Products, Nutrition and Allergies (NDA). General scientific guidance for stakeholders on health claim applications. EFSA J. 2016, 14, 4367.

49. Gakidou, E.; Afshin, A.; Abajobir, A.A.; Abate, K.H.; Abbafati, C.; Abbas, K.M.; Abd-Allah, F.; Abdulle, A.M.; Abera, S.F.; Aboyans, V.; et al. Global, regional, and national comparative risk assessment of 84 behavioural, environmental and occupational, and metabolic risks or clusters of risks, 1990-2016: A systematic analysis for the Global Burden of Disease Study 2016. Lancet 2017, 390, 1345-1422. [CrossRef]

50. Petersen, K.S.; Flock, M.R.; Richter, C.K.; Mukherjea, R.; Slavin, J.L.; Kris-Etherton, P.M. Healthy Dietary Patterns for Preventing Cardiometabolic Disease: The Role of Plant-Based Foods and Animal Products. Curr. Dev. Nutr. 2017, 1, cdn.117.001289. [CrossRef]

51. Angelino, D.; Godos, J.; Ghelfi, F.; Tieri, M.; Titta, L.; Lafranconi, A.; Marventano, S.; Alonzo, E.; Gambera, A.; Sciacca, S.; et al. Fruit and vegetable consumption and health outcomes: An umbrella review of observational studies. Int. J. Food Sci. Nutr. 2019, 70, 652-667. [CrossRef]

52. Oak, M.-H.; Auger, C.; Belcastro, E.; Park, S.-H.; Lee, H.-H.; Schini-Kerth, V.B. Potential mechanisms underlying cardiovascular protection by polyphenols: Role of the endothelium. Free Radic. Biol. Med. 2018, 122, 161-170. [CrossRef]

53. Schini-Kerth, V.B.; Auger, C.; Kim, J.-H.; Étienne-Selloum, N.; Chataigneau, T. Nutritional improvement of the endothelial control of vascular tone by polyphenols: Role of NO and EDHF. Pflüg. Arch. Eur. J. Physiol. 2010, 459, 853-862. [CrossRef]

54. Foito, A.; McDougall, G.J.; Stewart, D. Evidence for Health Benefits of Berries. Annu. Plant Rev. Online 2018, 1, 105-148.

55. Martini, D.; Marino, M.; Angelino, D.; Del Bo', C.; Del Rio, D.; Riso, P.; Porrini, M. Role of berries in vascular function: A systematic review of human intervention studies. Nutr. Rev. 2019, 78, 189-206. [CrossRef]

56. Del Bo', C.; Martini, D.; Porrini, M.; Klimis-Zacas, D.; Riso, P. Berries and oxidative stress markers: An overview of human intervention studies. Food Funct. 2015, 6, 2890-2917. [CrossRef]

57. Joseph, S.V.; Edirisinghe, I.; Burton-Freeman, B.M. Berries: Anti-inflammatory Effects in Humans. J. Agric. Food Chem. 2014, 62, 3886-3903. [CrossRef]

58. Fahmy, H.; Hegazi, N.; El-Shamy, S.; Farag, M.A. Pomegranate juice as a functional food: A comprehensive review of its polyphenols, therapeutic merits, and recent patents. Food Funct. 2020, 11, 5768-5781. [CrossRef]

59. Tenore, G.C.; Caruso, D.; Buonomo, G.; D’Urso, E.; D'Avino, M.; Campiglia, P.; Marinelli, L.; Novellino, E. Annurca (Malus pumila Miller cv. Annurca) apple as a functional food for the contribution to a healthy balance of plasma cholesterol levels: Results of a randomized clinical trial. J. Sci. Food Agric. 2017, 97, 2107-2115. [CrossRef]

60. Hosseini, B.; Saedisomeolia, A.; Wood, L.G.; Yaseri, M.; Tavasoli, S. Effects of pomegranate extract supplementation on inflammation in overweight and obese individuals: A randomized controlled clinical trial. Complement. Ther. Clin. Pract. 2016, 22, 44-50. [CrossRef] [PubMed] 
61. Fuster-Muñoz, E.; Roche, E.; Funes, L.; Martínez-Peinado, P.; Sempere, J.M.; Vicente-Salar, N. Effects of pomegranate juice in circulating parameters, cytokines, and oxidative stress markers in endurance-based athletes: A randomized controlled trial. Nutrition 2016, 32, 539-545. [CrossRef] [PubMed]

62. Ren, G.-Y.; Chen, C.-Y.; Chen, G.-C.; Chen, W.-G.; Pan, A.; Pan, C.-W.; Zhang, Y.-H.; Qin, L.-Q.; Chen, L.-H. Effect of Flaxseed Intervention on Inflammatory Marker C-Reactive Protein: A Systematic Review and Meta-Analysis of Randomized Controlled Trials. Nutrients 2016, 8, 136. [CrossRef]

63. Shoji, T.; Masumoto, S.; Moriichi, N.; Ohtake, Y.; Kanda, T. Administration of Apple Polyphenol Supplements for Skin Conditions in Healthy Women: A Randomized, Double-Blind, Placebo-Controlled Clinical Trial. Nutrients 2020, 12, 1071. [CrossRef] [PubMed]

64. Califf, R.M. Characteristics of Clinical Trials Registered in ClinicalTrials.gov, 2007-2010. JAMA 2012, 307, 1838. [CrossRef]

65. Roumiantseva, D.; Carini, S.; Sim, I.; Wagner, T.H. Sponsorship and design characteristics of trials registered in ClinicalTrials.gov. Contemp. Clin. Trials 2013, 34, 348-355. [CrossRef]

66. Turner, B.; Rajeshuni, N.; Tran, E.M.; Ludwig, C.A.; Tauqeer, Z.; Weeks, B.; Kinde, B.; Pershing, S. Characteristics of Ophthalmology Trials Registered in ClinicalTrials.gov, 2007-2018. Am. J. Ophthalmol. 2020, 211, 132-141. [CrossRef]

67. Allareddy, V.; Rampa, S.; Masoud, M.I.; Lee, M.K.; Nalliah, R.; Allareddy, V. Overview of registered studies in orthodontics: Evaluation of the ClinicalTrials.gov registry. Am. J. Orthod. Dentofac. Orthop. 2014, 146, 587-593. [CrossRef] [PubMed]

68. Goswami, N.D.; Pfeiffer, C.D.; Horton, J.R.; Chiswell, K.; Tasneem, A.; Tsalik, E.L. The State of Infectious Diseases Clinical Trials: A Systematic Review of ClinicalTrials.gov. PLoS ONE 2013, 8, e77086. [CrossRef] [PubMed]

69. Bourgeois, F.T. Outcome Reporting Among Drug Trials Registered in ClinicalTrials.gov. Ann. Intern. Med. 2010, 153, 158. [CrossRef]

70. Higgins, J.P.T.; Altman, D.G.; Gotzsche, P.C.; Juni, P.; Moher, D.; Oxman, A.D.; Savovic, J.; Schulz, K.F.; Weeks, L.; Sterne, J.A.C. The Cochrane Collaboration's tool for assessing risk of bias in randomised trials. BMJ 2011, 343, d5928. [CrossRef] [PubMed]

71. Tresserra-Rimbau, A.; Medina-Remón, A.; Pérez-Jiménez, J.; Martínez-González, M.A.A.; Covas, M.I.I.; Corella, D.; Salas-Salvadó, J.; Gómez-Gracia, E.; Lapetra, J.; Arós, F.; et al. Dietary intake and major food sources of polyphenols in a Spanish population at high cardiovascular risk: The PREDIMED study. Nutr. Metab. Cardiovasc. Dis. 2013, 23, 953-959. [CrossRef]

Publisher's Note: MDPI stays neutral with regard to jurisdictional claims in published maps and institutional affiliations.

(C) 2020 by the authors. Licensee MDPI, Basel, Switzerland. This article is an open access article distributed under the terms and conditions of the Creative Commons Attribution (CC BY) license (http://creativecommons.org/licenses/by/4.0/). 